\title{
Multiple Endocrine Neoplasia Type 1 Combined With Papillary Thyroid Carcinoma and Nodular Goiter: A Case Report and Review of The Literature
}

Jialu Xu

Jilin University First Hospital

Su Dong

Jilin University First Hospital

Zhe Han

Jilin University First Hospital

Lele Sun

Jilin University First Hospital

Jia Liu ( $\nabla$ sosea@sina.com )

Jilin University First Hospital https://orcid.org/0000-0002-4528-5199

\section{Case Report}

Keywords: case report, MEN1, thyroid cancer, papillary thyroid carcinoma, nodular goiter

Posted Date: October 22nd, 2020

DOI: https://doi.org/10.21203/rs.3.rs-92002/v1

License: (c) (i) This work is licensed under a Creative Commons Attribution 4.0 International License. Read Full License 


\section{Abstract}

Introduction: This is the first report of multiple endocrine neoplasia type 1 (MEN1) combined with papillary thyroid carcinoma (PTC) and nodular goiter in China. MEN1 is a rare hereditary tumor syndrome inherited in an autosomal dominant manner and presenting mostly as tumors of the parathyroid, endocrine pancreas (such as gastrinoma) and anterior pituitary. However, PTC and nodular goiter were not previously regarded as components.

Patient concerns: We present a 35-year-old woman with MEN1 accompanied with coinstantaneous PTC and nodular goiter.

Diagnosis: The pathological diagnosis was PTC with cervical lymph node metastasis, nodular goiter, parathyroid cyst and adenomatoid hyperplasia. Genetic analysis was performed and a germ-line MEN1 gene mutation was detected.

Interventions: The patient underwent unilateral lobectomy of the thyroid gland and surgical removal of the parathyroid tumors.

Outcomes: After 6 months of follow-up, ultrasonic examination of the patient's neck showed no abnormality. Serum calcium and parathyroid hormone levels were normal.

Conclusion: This is the first experience of a case of MEN1 combined with PTC and nodular goiter in China. MEN1 syndrome may have predisposed the present patient to PTC and nodular goiter. PTC and/or nodular goiter may be new components of MEN1. More cases are required to confirm this association.

\section{Introduction}

Multiple endocrine neoplasia type 1 (MEN1) is a rare hereditary tumor syndrome inherited in an autosomal dominant manner and characterized by a predisposition to a multitude of endocrine neoplasms, mostly of the parathyroid, endocrine pancreas and anterior pituitary. Other endocrine tumors in MEN1 include gastroenteropancreatic neuroendocrine tumors (GEP-NET), adrenocortical tumors, and rarely pheochromocytoma [1-3]. MEN1 is caused by inactivating mutations of MEN1 gene. The incidence is 1/10 000-1/100 000. MEN1 is a tumor suppressor gene and is located on human chromosome 11q13. MEN1 gene is $9 \mathrm{~kb}$ and contains 10 exons. Exons 2-10 are coding regions. MEN1 gene encodes the protein menin, which contains 610 amino acids $[4,5]$. Menin plays an important role in cell division and proliferation, cell cycle regulation and genomic stability. Mutation of MEN1 gene can lead to loss of function of menin, and occurrence of multiple tumors [6-10]. Gene mutation analysis is an important diagnostic method for MEN1 [1].

It has been reported that expression of menin is preserved in human normal thyroid tissue and thyroid tumors, but it can be decreased or absent in certain types of thyroid tumors [11-14]. Currently, little is 
known about the prevalence of thyroid tumors in MEN1 patients and it is unclear whether tumorigenesis of these thyroid tumors is MEN1 related.

Here, we present a patient with MEN1 accompanied by coinstantaneous PTC and nodular goiter.

\section{Case Presentation}

The present study was approved by the Institutional Ethics Committee of the First Hospital of Jilin University. The patient provided written consent to publish the case. The patient was a 35-year-old woman who presented with a neck mass 4 days after physical examination, without complaining about abnormal feelings due to high calcium and parathyroid hormone. The patient immediately came to our hospital after discovery of the neck tumor, without any intervention measures. Partial resection of the pancreas and stomach had been performed for pancreatic gastroduodenal neuroendocrine tumor 4 years ago. The patient had a history of pituitary microadenoma for 2 years. Her father had stomach surgery, but we do not know the details since he died 20 years ago. Other relatives of the patient had no symptoms of MEN1 syndrome. Neck ultrasound suggested a $64 \mathrm{~mm} \times 28 \mathrm{~mm} \times 45 \mathrm{~mm}$ cystic mass located below the right lobe of the thyroid gland with a well-defined smooth border and several solid nodules were detected in right thyroid lobe, with the largest $(18 \mathrm{~mm} \times 10 \mathrm{~mm} \times 8 \mathrm{~mm})$ in the right lower thyroid lobe. The largest nodule in the thyroid had an unclear boundary, dotted calcification and abundant internal blood flow (Fig. 1A and B). Computed tomography (CT) or magnetic resonance imaging (MRI) examination showed: head: changes in pituitary region; neck: lesions in thyroid gland right lobe and superior mediastinum; and abdomen: changes after partial gastrectomy and in the tail of the pancreas (Fig. 2A-D). In 99mTcmethoxyisobutyl isonitrile scintigraphy, tracer uptake was increased in the right lower region of the thyroid gland and mediastinum, and images showed no abnormal retention of the tracer in the late phase. No uptake was detected in other regions. Preoperative sestamibi single-photon emission computed tomography (SPECT)/CT found a lesion in the lower thyroid gland right lobe and part of which extended to the superior mediastinum (Fig. 3A). Bone scanning showed: T-scores -2.6 and Z-scores -2.0 . The results of biochemical tests were as follows: serum calcium $2.82 \mathrm{mmol} / \mathrm{L}$ (reference range: $2.11-$ $2.52 \mathrm{mmol} / \mathrm{L}$ ); albumin $47.7 \mathrm{~g} / \mathrm{L}$ (reference range: $40-55 \mathrm{~g} / \mathrm{L}$ ); serum intact parathyroid hormone (iPTH) elevated to $676.3 \mathrm{pg} / \mathrm{mL}$ (reference range: $12-88 \mathrm{pg} / \mathrm{mL}$ ); gastrin 17: $0.8 \mathrm{pmol} / \mathrm{L}$ (reference range: 1$15 \mathrm{pmol} / \mathrm{L}$ ); normal thyroid function normal; thyroid peroxidase antibody (TPO Ab): $23.98 \mathrm{lU} / \mathrm{ml}$ (reference range: $<35 \mathrm{IU} / \mathrm{ml}$ ).

Because the patient had a large neck mass, her serum calcium and iPTH levels were significantly abnormal and several solid nodules were detected in the right thyroid lobe (the largest nodules were suspected to be malignant by ultrasound and rapid intraoperative pathological diagnosis confirmed PTC). Parathyroidectomy and unilateral thyroid lobectomy were recommended and performed with the patient's consent. The clinical features of hyperparathyroidism (HPT) with MEN1 are similar to those with sporadic HPT, but the formers are often more aggressive. For patients who have HPT with MEN1, it is better to have early surgical treatment. Asymptomatic patients should consider surgical treatment when (1) serum calcium is higher than the reference range $2.52 \mathrm{mmol} / \mathrm{L}$; (2) glomerular filtration $<60 \mathrm{ml} / \mathrm{min}$; 
(3) bone mineral density at any point is -2.5 or lower, or patient has fragility fractures; and (4) age < 50 years. Whether early surgery can reduce the incidence rate and mortality is not clear. For patients who have HPT with MEN1, especially in asymptomatic or mild and young patients, early parathyroidectomy can reduce the long-term effects of HPT, especially in reducing bone loss. Although fine needle aspiration (FNA) is the most useful means for diagnosis of a thyroid nodule, it is not generally accepted for diagnosis of parathyroid tumor due to the risk of dissemination of parathyroid cells, especially in parathyroid cancer. What's more, the patient refused to accept FNA of the thyroid nodule before the operation to avoid additional injury and hope to perform rapid intraoperative pathological diagnosis with parathyroid. During the operation, gross examination of the largest cyst showed it to be partially surrounded and contiguous with the right lower thyroid lobe and extended to the superior mediastinum, and it peeled off easily from the right lower thyroid lobe and mediastinum. Furthermore, it was filled with clear watery fluid, suggesting that it was a parathyroid cyst (Fig. 3B). The largest cyst and right lobe of the thyroid were removed. The left lower parathyroid gland was explored during the operation and was diagnosed with hyperplasia after resection. Intraoperative frozen section pathology reported that the largest cyst was the source of parathyroid and papillary thyroid carcinoma, and nodular goiter was found in the thyroid right lobe, and the left lower parathyroid was diagnosed with adenomatoid hyperplasia. The central lymph nodes were cleared (4/5 with cancer metastasis). We tested serum iPTH at 20 min after resection and iPTH was $253.4 \mathrm{pg} / \mathrm{mL}$. Other parathyroid glands were explored. Two upper parathyroid glands were normal. The left lower parathyroid was enlarged and removed. Rapid intraoperative pathological analysis revealed was adenomatoid hyperplasia. After another $20 \mathrm{~min}$, serum iPTH decreased to $63.9 \mathrm{pg} / \mathrm{mL}$. The postoperative pathological results were consistent with the rapid intraoperative pathological results (Fig. 4). The laboratory data on postoperative day 2 showed calcium was $1.98 \mathrm{mmol} / \mathrm{L}$ and $\mathrm{iPTH}$ was $24.1 \mathrm{pg} / \mathrm{ml}$. After taking $1.5 \mathrm{~g}$ calcium carbonate daily for 3 months, the patient's laboratory data improved, as follows: calcium $1.98 \mathrm{mmol} / \mathrm{L}$ and $\mathrm{iPTH} 43.7 \mathrm{pg} / \mathrm{ml}$. Calcium was $2.47 \mathrm{mmol} / \mathrm{L}$ and $\mathrm{PPTH}$ was $61 \mathrm{pg} / \mathrm{ml}$ after 18 months. After the operation, genetic analysis was performed to determine the association between gene mutations and the development of tumors in this patient, and a germline MEN1 gene mutation was detected. The patient gave informed consent and the Institutional Review Board approved the present study before genetic analysis. During follow-up, there was no hypoparathyroidism or other complications. One month after the operation, the demand for levothyroxine was reduced from 75 to $50 \mu \mathrm{g}$.

\section{Discussion}

Currently, little is known about the risk of concomitant thyroid cancer or benign thyroid nodules in MEN1 patients. Our case provides practical evidence that MEN1 and thyroid tumors may coexist. MEN1 is a rare hereditary tumor syndrome inherited in an autosomal dominant manner and presents mostly as tumors of the parathyroid[15], endocrine pancreas (such as gastrinoma) [16] and anterior pituitary[17]. Other endocrine and nonendocrine lesions of MEN1, such as adrenal cortical tumors; carcinoids of the bronchi, gastrointestinal tract and thymus; lipomas; angiofibromas; and collagenomas have been described [1, 18]. As the thyroid is not among the affected glands of MEN1 syndrome, studies do not systematically 
collect data regarding its pathology, thus leading to controversial data in the literature. Hill et al. reported that patients with MEN1 had a $28 \%$ incidence of thyroid cancer and underwent more unplanned thyroidectomies during parathyroidectomy [19]. Lodewijk et al. considered that MEN1 patients do not have a higher prevalence of thyroid incidentalomas compared with primary hyperparathyroidism patients without a diagnosis of MEN1 [14]. MEN1 is caused by inactivating mutations of the MEN1 gene that encodes the protein menin [2]. One study showed that menin was positive in immunohistochemical staining in five thyroid tumors, including hyperplastic nodules, microinvasive medullary thyroid carcinoma (MTC), microinvasive follicular thyroid carcinoma (FTC), multinodular goiter and follicular adenoma [14]. Menin is a nuclear protein whose interaction with several other nuclear proteins indicates a role in transcriptional regulation. Previous studies have supported a role for MEN1 in the control of cell growth and differentiation, and in sensing or repairing DNA damage. The loss of menin function in a tumor precursor cell is involved in the mechanism for tumor formation in MEN1 [8-10, 20-22]. Further molecular studies are needed to evaluate to potential of menin protein in thyroid tumorigenesis and the relationship between these thyroid tumors and MEN1. The expression of menin is generally preserved in human thyroid carcinoma and can be decreased or absent in certain types of thyroid cancer including PTC [11]. The inactivation of menin in the thyroid gland of young mice influenced the proliferation of follicular cells [13].

Here, we present a rare case of MEN1 with a large functioning parathyroid cyst. Cavalli et al. found that approximately 300 cases of sporadic parathyroid cyst (PCs) had been reported to 2017. Only two cases have been described in MEN1 [15]. Parathyroid cysts can be divided into functioning and nonfunctioning, and most parathyroid cysts are nonfunctioning. Functioning cysts are more likely to be caused by degenerative changes in parathyroid adenoma than hyperplasia [23]. In many cases, it is difficult to diagnose the nature of the cyst just by ultrasound. Parathyroid cysts need to be differentiated from lymphatic cysts, cystic thyroid nodules and hemangioma [24,25]. The diagnostic rate can be improved by laboratory examination and other imaging examinations. Preoperative SPECT/CT is useful in localizing parathyroid cysts in most patients, with accuracy improving to $79 \%$ if it is interpreted in combination with cervical ultrasound images [26]. Two different forms of MEN1, sporadic and familial, have been described [27]. The sporadic form presents with two of the three principal MEN1-related endocrine tumors (parathyroid adenoma, enteropancreatic tumor and pituitary tumor) within a single patient, while the familial form consists of MEN1 with at least one first-degree relative showing one of the endocrine characteristic tumors [28-31]. In our case, the patient did not provide a clear family history. So it is still unclear what form of MEN1 our patient has. There is no evidence to exclude the accidental occurrence of MEN1 with PTC in this patient. Based on the current reports of the correlation between the inactive menin status and human thyroid carcinoma, menin can be decreased or absent in certain types of thyroid cancer including PTC [11] and the inactivation of menin in the thyroid gland influences the proliferation of follicular cells [13], we also supposed that PTC and nodular goiter might be considered as new component of MEN1. However, there is no evidence to confirm it now for the rare incidence.In the future, we hope to summarize the statistical significance of PTC and MEN1 as the number of cases reported 
worldwide increases. We will screen the immediate family members of the patient to clarify the form of MEN1 and look for more cases.

\section{Conclusion}

In summary, we presented a rare case of MEN1 associated with PTC and nodular goiter, in which a germline mutation of the MEN1 gene was detected. In this patient, MEN1 syndrome may have predisposed the patient to developing PTC and nodular goiter. Further studies and additional case reports are required to clarify this connection.

\section{Abbreviations}

MEN1: multiple endocrine neoplasia type 1; PTC: papillary thyroid cancer; HPT: hyperparathyroidism; FNA: fine needle aspiration; iPTH: intact parathyroid hormone; MTC: microinvasive medullary thyroid carcinoma, FTC: microinvasive follicular thyroid carcinoma.CT:Computed tomography; MRI: magnetic resonance imaging

\section{Declarations}

\section{Acknowledgements}

We owe thanks to the patients and his family.

\section{Funding}

There are no funding sources for this case report.

\section{Author Contributions}

JX and JL wrote the manuscript and all author listed have made a substantial, direct and intellectual contribution to the work, and approve it for publication.

\section{Competing interests}

The authors declare that they have no competing interests.

\section{Availability of data and materials}

Not applicable.

\section{Ethics approval and consent to participate}

The present study was approved by the Institutional Ethics Committee of the First Hospital of Jilin University. The patient provided written consent to publish the case. 


\section{Consent for publication}

Written informed consent for publication of the clinical details and/or clinical images was obtained from the patient.A copy of the consent form is available for review by the Editor of this journal.

\section{Author details}

${ }^{1}$ Department of Thyroid Surgery, the First Hospital of Jilin University, Changchun,

China

${ }^{2}$ Department of Anesthesia, the First Hospital of Jilin University, Changchun, China

* Correspondence to:

Jia Liu

E-mail:sosea@sina.com

\section{References}

1. F. Marini, A. Falchetti, F. Del Monte, S. Carbonell Sala, A. Gozzini, E. Luzi, and M.L. Brandi, Multiple endocrine neoplasia type 1. Orphanet J Rare Dis 1 (2006) 38.

2. C.D.C. Kamilaris, and C.A. Stratakis, Multiple Endocrine Neoplasia Type 1 (MEN1): An Update and the Significance of Early Genetic and Clinical Diagnosis. Front Endocrinol (Lausanne) 10 (2019) 339.

3. F. Giudici, T. Cavalli, F. Giusti, G. Gronchi, G. Batignani, F. Tonelli, and M.L. Brandi, Natural History of MEN1 GEP-NET: Single-Center Experience After a Long Follow-Up. World J Surg 41 (2017) 23122323.

4. A. Al-Salameh, C. Baudry, and R. Cohen, Update on multiple endocrine neoplasia Type 1 and 2. Presse Med 47 (2018) 722-731.

5. T. Tsukada, Y. Nagamura, and N. Ohkura, MEN1 gene and its mutations: basic and clinical implications. Cancer Sci 100 (2009) 209-15.

6. S.J. Marx, Recent Topics Around Multiple Endocrine Neoplasia Type 1. J Clin Endocrinol Metab 103 (2018) 1296-1301.

7. J. Suzuki, T. Yamada, K. Inoue, S. Nabe, M. Kuwahara, N. Takemori, A. Takemori, S. Matsuda, M. Kanoh, Y. Imai, M. Yasukawa, and M. Yamashita, The tumor suppressor menin prevents effector CD8 T-cell dysfunction by targeting mTORC1-dependent metabolic activation. Nat Commun 9 (2018) 3296.

8. J.W.Y. Li, X. Hua, D. Reidy-Lagunes, and B.R. Untch, MENIN loss as a tissue-specific driver of tumorigenesis. Mol Cell Endocrinol 469 (2018) 98-106. 
9. P. Cheng, G. Li, S.S. Yang, R. Liu, G. Jin, X.Y. Zhou, and X.G. Hu, Tumor suppressor Menin acts as a corepressor of LXRalpha to inhibit hepatic lipogenesis. FEBS Lett 589 (2015) 3079-84.

10. K.M.A. Dreijerink, A.C. Groner, E.S.M. Vos, A. Font-Tello, L. Gu, D. Chi, J. Reyes, J. Cook, E. Lim, C.Y. Lin, W. de Laat, P.K. Rao, H.W. Long, and M. Brown, Enhancer-Mediated Oncogenic Function of the Menin Tumor Suppressor in Breast Cancer. Cell Rep 18 (2017) 2359-2372.

11. O.M. Capraru, M. Decaussin-Petrucci, M.O. Joly, A. Borda, I.S. Fanfaret, F. Borson-Chazot, and S. Selmi-Ruby, Expression of Menin in the Human Thyroid Gland. Acta Endocrinol (Buchar) 13 (2017) 154-160.

12. D. Desai, L.A. McPherson, J.P. Higgins, and R.J. Weigel, Genetic analysis of a papillary thyroid carcinoma in a patient with MEN1. Ann Surg Oncol 8 (2001) 342-6.

13. O.M. Capraru, N. Berger, N. Gadot, M. Decaussin-Petrucci, C. Zhang, A. Borda, T. Szilagyi, F. BorsonChazot, and S. Selmi-Ruby, Histopathological changes induced by selective inactivation of menin on the thyroid gland in RET/PTC3 and E7 transgenic mice. A study of 77 cases. Rom J Morphol Embryol 57 (2016) 91-8.

14. L. Lodewijk, P.J. Bongers, J.W. Kist, E.B. Conemans, J.M. de Laat, C.R. Pieterman, A.N. van der HorstSchrivers, C. Jorna, A.R. Hermus, O.M. Dekkers, W.W. de Herder, M.L. Drent, P.H. Bisschop, B. Havekes, I.H. Rinkes, M.R. Vriens, and G.D. Valk, Thyroid incidentalomas in patients with multiple endocrine neoplasia type 1. Eur J Endocrinol 172 (2015) 337-42.

15. T. Cavalli, F. Giudici, G. Nesi, A. Amorosi, R. Santi, M.L. Brandi, and F. Tonelli, Cystic parathyroid glands in MEN1: A rare entity? Fam Cancer 16 (2017) 249-256.

16. T. Ito, H. Igarashi, H. Uehara, M.J. Berna, and R.T. Jensen, Causes of death and prognostic factors in multiple endocrine neoplasia type 1: a prospective study: comparison of $106 \mathrm{MEN1/Zollinger-Ellison}$ syndrome patients with 1613 literature MEN1 patients with or without pancreatic endocrine tumors. Medicine (Baltimore) 92 (2013) 135-81.

17. B. Delemer, MEN1 and pituitary adenomas. Ann Endocrinol (Paris) 73 (2012) 59-61.

18. R.W. Carroll, Multiple endocrine neoplasia type 1 (MEN1). Asia Pac J Clin Oncol 9 (2013) 297-309.

19. K.A. Hill, L. Yip, S.E. Carty, and K.L. McCoy, Concomitant Thyroid Cancer in Patients with Multiple Endocrine Neoplasia Type 1 Undergoing Surgery for Primary Hyperparathyroidism. Thyroid 29 (2019) 252-257.

20. M. Razmara, A. Monazzam, and B. Skogseid, Reduced menin expression impairs rapamycin effects as evidenced by an increase in mTORC2 signaling and cell migration. Cell Commun Signal 16 (2018) 64.

21. K.M.A. Dreijerink, H.T.M. Timmers, and M. Brown, Twenty years of menin: emerging opportunities for restoration of transcriptional regulation in MEN1. Endocr Relat Cancer 24 (2017) T135-T145.

22. G. Wu, M. Yuan, S. Shen, X. Ma, J. Fang, L. Zhu, L. Sun, Z. Liu, X. He, Huang, T. Li, C. Li, J. Wu, X. Hu, Z. Li, L. Song, K. Qu, H. Zhang, and P. Gao, Menin enhances c-Myc-mediated transcription to promote cancer progression. Nat Commun 8 (2017) 15278. 
23. H. Tamiya, M. Miyakawa, H. Suzuki, A. Takeshita, K. Ohashi, T. Usui, D. Miura, and Y. Takeuchi, A large functioning parathyroid cyst in a patient with multiple endocrine neoplasia type 1. Endocr $\mathrm{J} 60$ (2013) 709-14.

24. T.S. Papavramidis, A. Chorti, I. Pliakos, S. Panidis, and A. Michalopoulos, Parathyroid cysts: A review of 359 patients reported in the international literature. Medicine (Baltimore) 97 (2018) e11399.

25. A. Arduc, Y.A. Tutuncu, B.A. Dogan, A.B. Arikan lleri, M.M. Tuna, H.N. Ozcan, S. Isik, D. Berker, and S. Guler, Parathyroid cysts. Am Surg 81 (2015) E163-5.

26. N.A. Johnson, L. Yip, and M.E. Tublin, Cystic parathyroid adenoma: sonographic features and correlation with 99mTc-sestamibi SPECT findings. AJR Am J Roentgenol 195 (2010) 1385-90.

27. A. Makri, M.B. Bonella, M.F. Keil, L. Hernandez-Ramirez, G. Paluch, A. Tirosh, C. Saldarriaga, P. Chittiboina, S.J. Marx, C.A. Stratakis, and M. Lodish, Children with MEN1 gene mutations may present first (and at a young age) with Cushing disease. Clin Endocrinol (Oxf) 89 (2018) 437-443.

28. G.N. Hendy, and D.E. Cole, Genetic defects associated with familial and sporadic hyperparathyroidism. Front Horm Res 41 (2013) 149-65.

29. H. Beijers, N.M.L. Stikkelbroeck, A.R. Mensenkamp, R. Pfundt, R.B. van der Luijt, H. Timmers, A. Hermus, and M.J.E. Kempers, Germline and somatic mosaicism in a family with multiple endocrine neoplasia type 1 (MEN1) syndrome. Eur J Endocrinol 180 (2019) K15-K19.

30. A. Horvath, and C.A. Stratakis, Clinical and molecular genetics of acromegaly: MEN1, Carney complex, McCune-Albright syndrome, familial acromegaly and genetic defects in sporadic tumors. Rev Endocr Metab Disord 9 (2008) 1-11.

31. W. Karges, K. Jostarndt, S. Maier, A. Flemming, M. Weitz, A. Wissmann, B. Feldmann, H. Dralle, P. Wagner, and B.O. Boehm, Multiple endocrine neoplasia type 1 (MEN1) gene mutations in a subset of patients with sporadic and familial primary hyperparathyroidism target the coding sequence but spare the promoter region. J Endocrinol 166 (2000) 1-9.

\section{Figures}




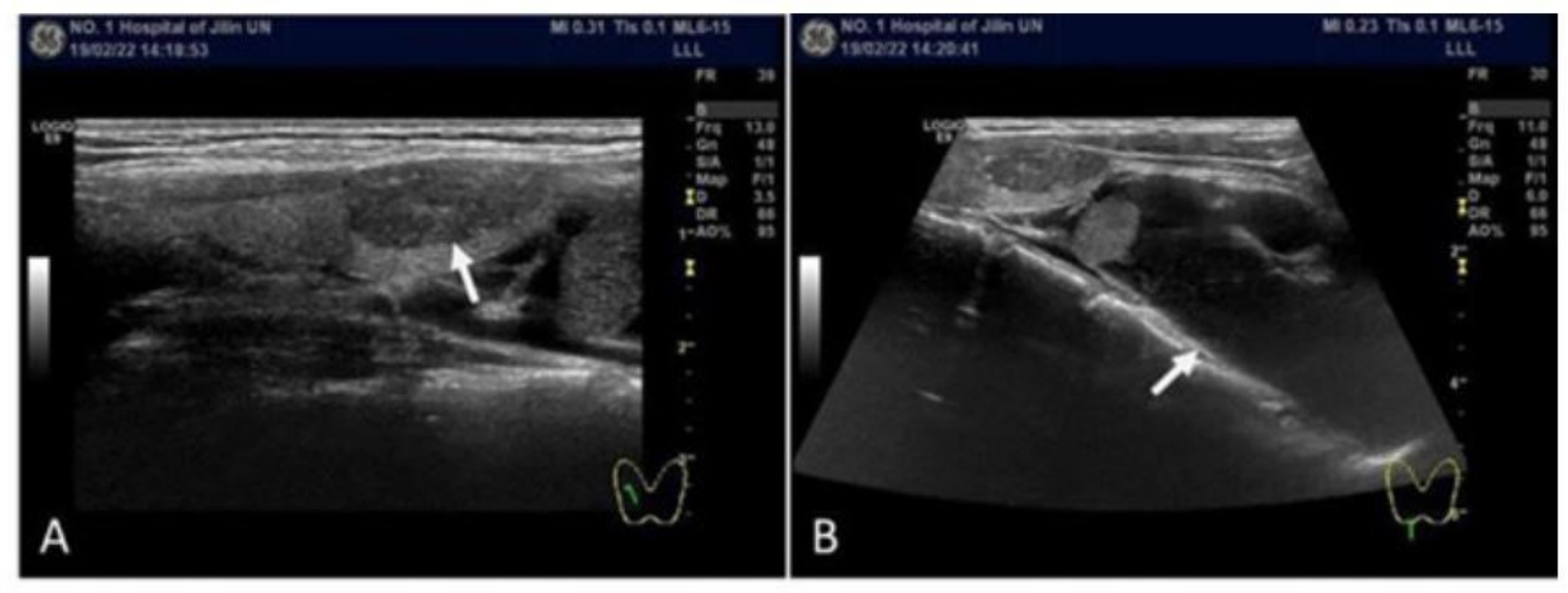

\section{Figure 1}

Thyroid ultrasonography demonstrated A: solid nodule with multiple punctate microcalcifications and relatively regular shape within the right lobe of the thyroid (arrow). B: huge cystic mass with clear boundaries located in the lower right lobe of the thyroid (arrow). 

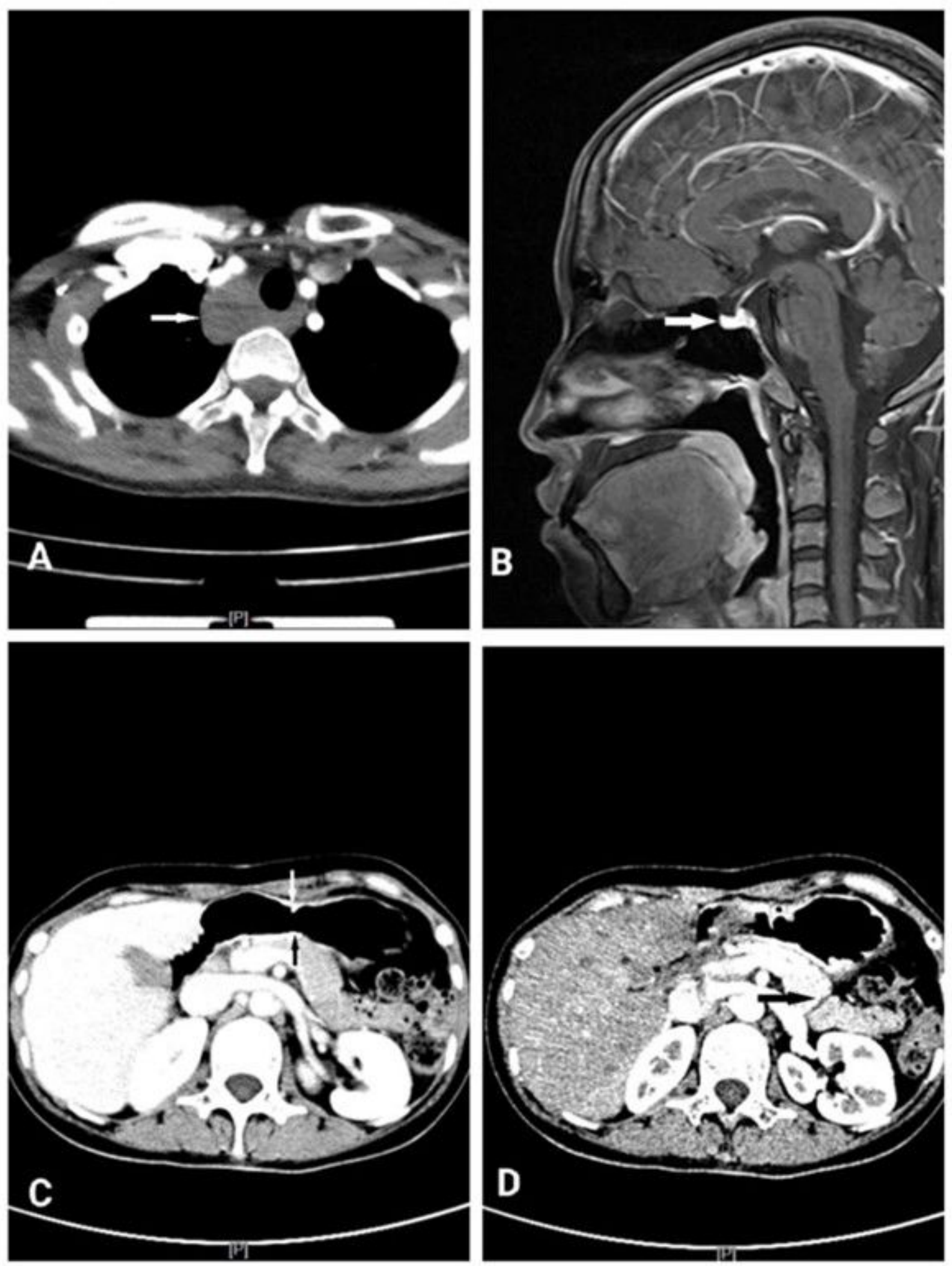

Figure 2

$\mathrm{CT} / \mathrm{MRI}$ examination. A: lesion located in the right side of the trachea (arrow). B: enlarged pituitary structure (arrow). C: remnant stomach anastomosed to the jejunum (arrow). D: remnant pancreas body and tail (arrow). 

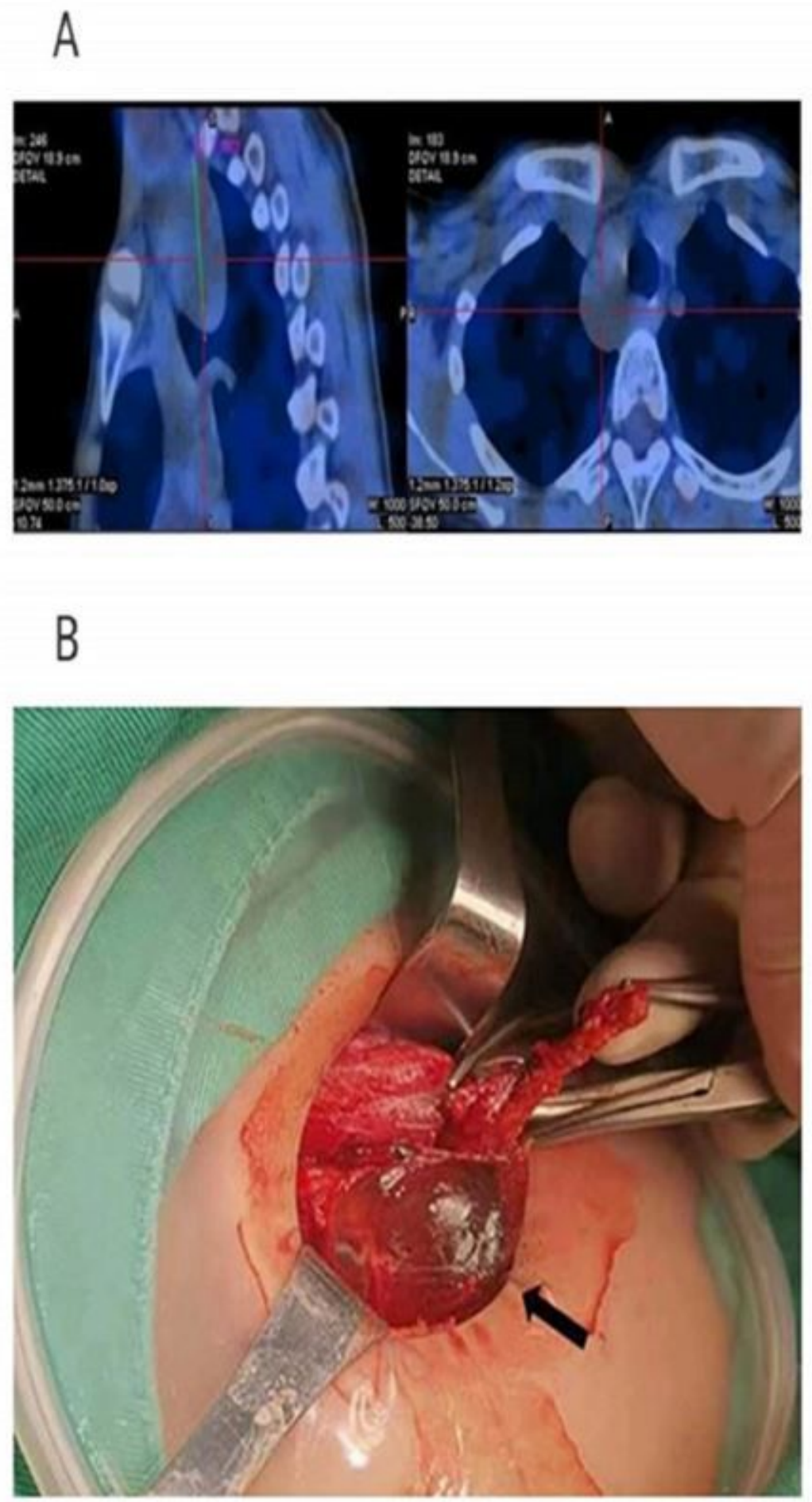

\section{Figure 3}

A: SPECT/CT revealed that the lesion was located in the lower thyroid gland right lobe and superior mediastinum. B: large cyst was filled with clear watery fluid and contiguous with the lower right lobe of the thyroid gland (arrow). 

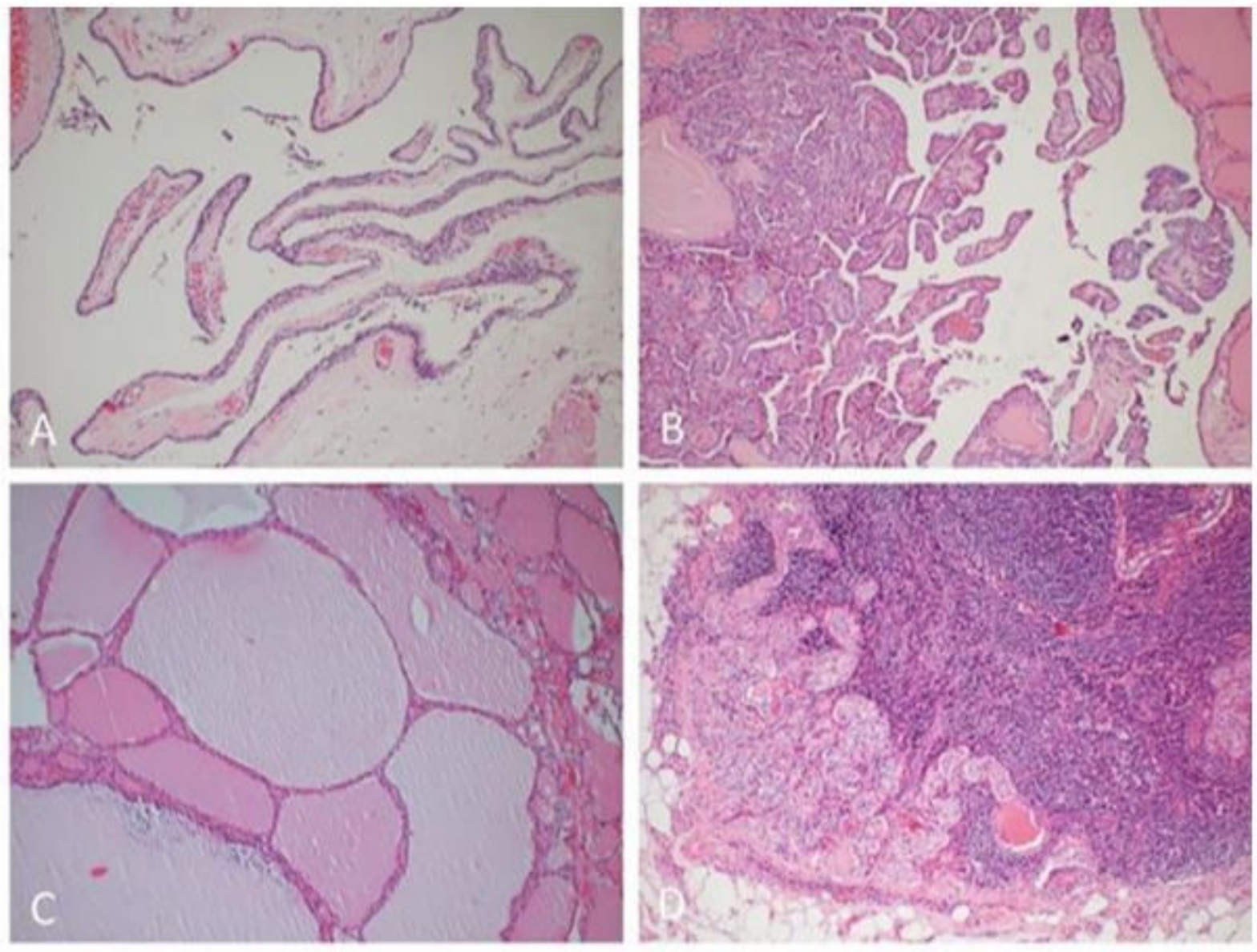

\section{Figure 4}

Histopathological examination. A: parathyroid cyst: a single locular cystic mass covered by a single layer of flattened transparent cells with small clusters of extruded parathyroid tissue in the wall. B: thyroid papillary carcinoma: complex branching papilla with fibrous vascular center, surface coated with simple columnar epithelium. C: nodular goiter: the follicles vary in size and are filled with colloid. D: metastatic lesions of thyroid papillary carcinoma in lymph nodes. (HE staining, 100×magnification).

\section{Supplementary Files}

This is a list of supplementary files associated with this preprint. Click to download.

- CAREchecklistEnglish20131zhong1.pdf 